\title{
بنية الشخصية في القصيلة الشعرية عند الهذليين مستخلص من رسالة ماجستير: \\ (بنية القص في الخطاب الشعري شعر الهذليين نموذجا)

\author{
إعداد
}

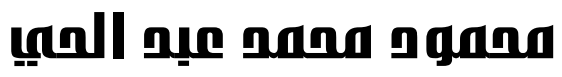

باحث ماجستير - قسهر الد راسات الأدبيتم

\section{إشـــــــ}

פ/

أستاذ المساعد بكليت دار العلوه جامعت الفيوهر

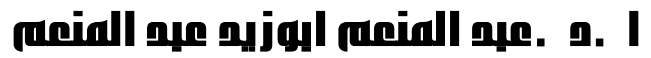
أستاذ بكليت دار العلوه جامعت الفيوه 


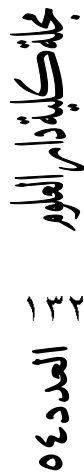




\section{مقدمة:}

الحمد لله رب العالمين، والصلاة والسلام على خحاتم الأنبياء والمرسلين، نبينا

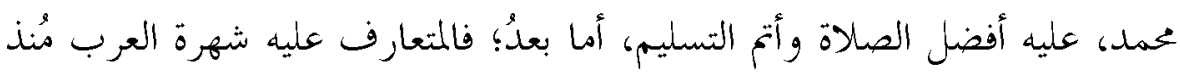

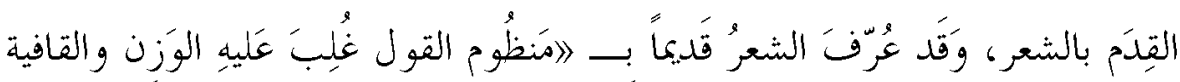

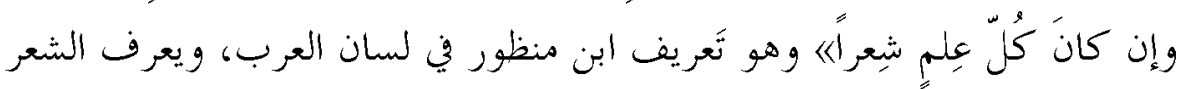

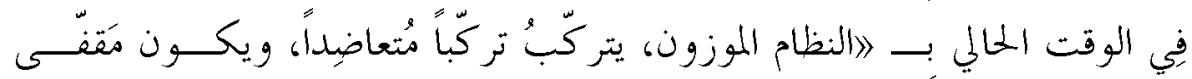

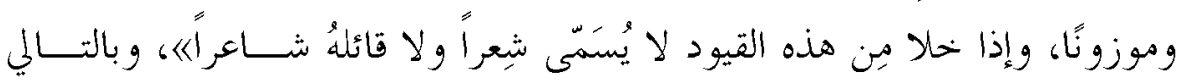
هناك أربعة شروط للشعر هي: المحتي، والوزن، والقافية، والقَصِد .

ومن ثم كانت له مكانة خاصة وأهية عند رواده العرب وعلى سبيل الــــكر لا لا الحصر:

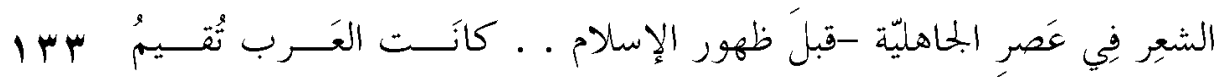

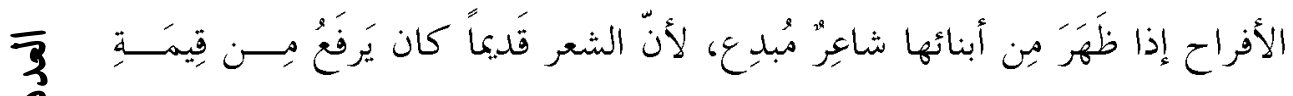

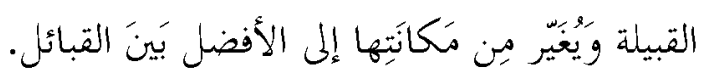

ومن الوظائف المشهورة المهمة للشعر هو حماية القبيلة، والــدفاع عنـــها،

وإظهار شرفها. والشعر مصدر" للمعرفة، والفكر، والحكمة، ومن الوظائف المهمة

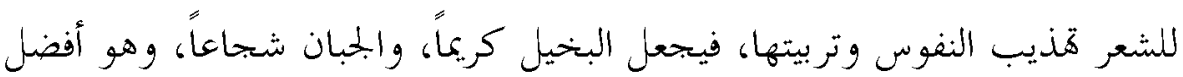
و سيلة لحفظ اللغة، و تفصيح اللسان، منه تُتِّخَخْ الشّو اهد و والأمثال. وتأسيسا على ذلك فالشعر يعد الفن الأكبر من فنون الأدب والأكثر رواجاً

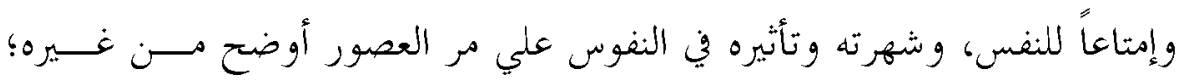

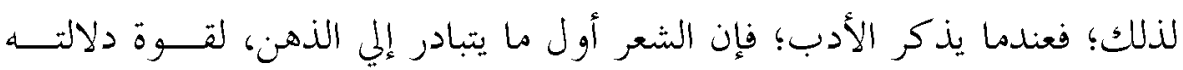
عليه، نقد حفظ الشعر الأبجاد والبطولات والثقافات والمذاهب والأحداث، فكما 
كانت الأمم السابقة تخلد مآثرها بالبنيان والخعصون، فإن العربـ يعتمـــــو علـــي الشعر في حفظ المياة الأدبية بجميع أجناسها المختلغة. وعلى أية حال فالشعر ديوان العرب، وسجل تاريّهم، و لمجيزل الإقبال عليه

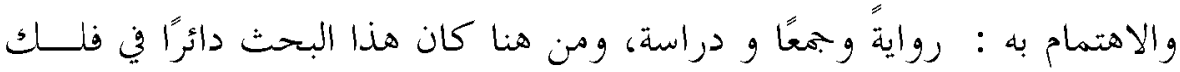

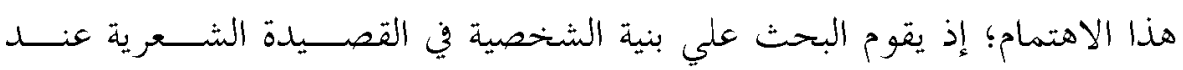
الهiلين.

فاستخدم الشاعر القلديم بعض العناصر الدرامية والسردية في شعره بعفويـــة

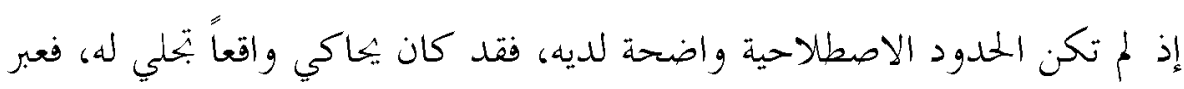
عنه بتلقائية وعفوية، بطريقة فنية مائزة احتضنت طاقة درامية سردية أغنت الشعر،

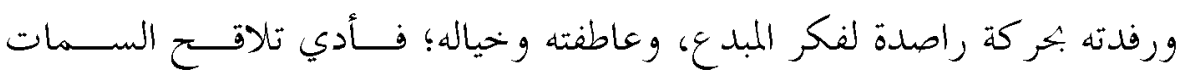
الدرامية والسردية في النص الشعري إلي خلق أسلوب شعري جديد يجسد انفتاح النص الشعري علي أنواع أدبية أخري، تحقق آلية بتاوزه مع النثر بوصفه الجلــنس الأدبي المغارق له، فاجتمعت عناصر السرد والوصف والحوار وغيرها في قصــائد كثيرة من أشعار هذيل، فتل تعانق فيها السرد بوجهه الحلكائي القصصي الشــائق مع البعد الدرامي ذي الطابع التراجيدي الخاص، وانصهرا في نسيج القصيدة؛ ليغنيا الأساليب الفنية، ويساعدا علي بتمسيد التجربة.

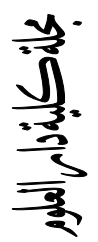

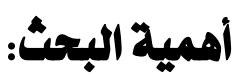

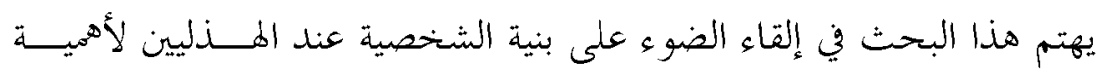
هذيل نفسها و بطوها و وكانتهم بين ديار العرب ولا لليهم من أكابر الشــعراء في زماهم اللذين قرضوا شعراً جيداً شهل به القاصى، يهدف هذا البحث إلي الكشف عن عنصر بنية الشخصية الكامنة في بنية النص الشعري القلهم، وبيان أهميتـــا في 
تفعيل رؤي المبدع، والتعبير عن بعض ألوان الصراع الدرامي الذي كان يعيشه، لا

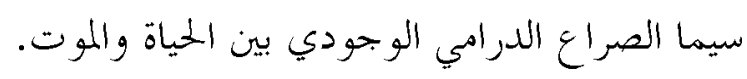

ويلقي البحث الضوء علي إمكانية بتحاوز الخطاب الخكائي ضمن بنية النص

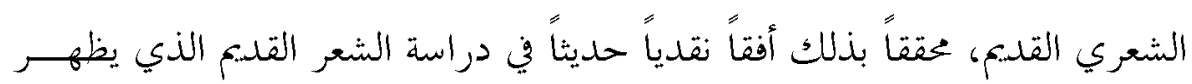
فيه نوع من التداخل مع النثر عبر توظيفه التلقائي مكونات درامية وسردية مختلفة أبرزها بنية الشخصية داخل النص الشعري.

منمبع البحثث: استخدمت في البحث المنهج الوصفى التحليلى.

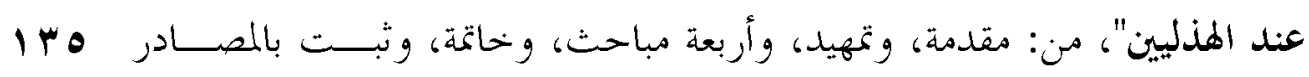

$\overline{3}$
3
0
0

\section{خمطة البحكث:}

يتكون هذا البحث الذي هو بعنوان: " بنية الشخصية في القصيدة الثعرية

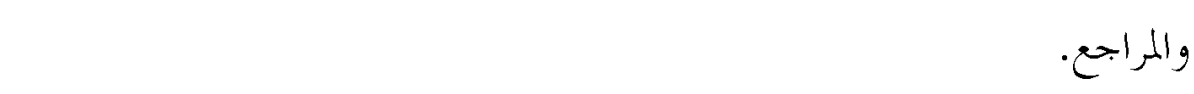

المقدمة: تتضمن أهمية الشعر بالنسبة للعرب عامة، وهذيل خاصة، ثم أهميــة

$$
\text { الموضوع وأسباب اختياره، ومنهج البحث. }
$$

التمهيد: وتحدثت فيه عن أهمية الشخصية وبنيتها، ومدى أهميتــها داخهـل الشعر.

المبحث الأول: تضمن علاقة الشخصية بالشخصية، وأوضحت فيه نـــوعين

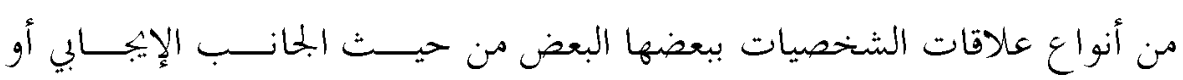
السلبي.

المبحث الثامي: أوضحت فيه علاقة الشخصية بالحدث، ومدي تـأثر كـل منهما بالآخر، من تأتير الشخصية على الحدث، أو تأثير الحدث علي الشخصية. 
المبحث الثالث: تحدثت فيه عن علاقة الشخصية بالزمان، وتلازمهما الدائم

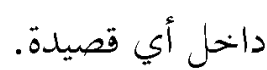

المبحث الرابع: وفيه تناولت علاقة الشخصية بالمكان، واتساقهما دائماً علي

$$
\text { خط واحد وأهمية كل منهما للآخر. }
$$

الشخصية هي محور العمل القصصي والبناء الحلكائي ومن أهم ركائزها هــــ

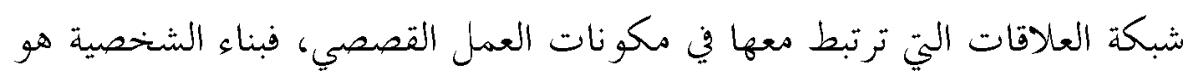
من يجدد اللغة المستخدمة في الخطاب، فالعمل القصصي " ينهض على طائفة مــن الخصائص والتقنيات والعناصر والمشكلات: كالشخصية، والحبككـة، والزمهــان،

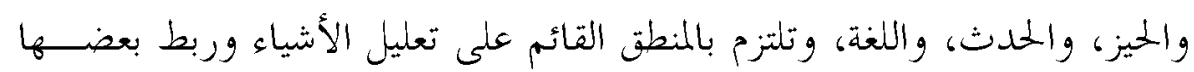
ببعض ") (1)

"فكأن الشخصية في القصة الشعرية كانت هي كل شئ؛ بحيث لايمكـــن أن 1 ry نتصور رواية دون طغيان شخصية مثيرة يقحمها الشاعر فيها؛ والسعي إلى إعطائها

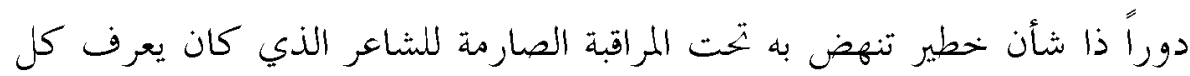

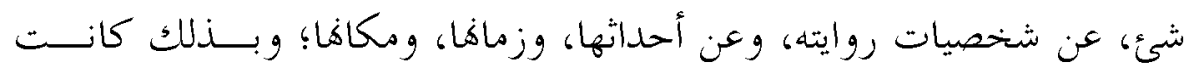
الشخصية تلعب الدور الأكبر في أي عمل شعري" ونهي". فالشخصية هي الركيزة الأولي والأساسية في العمل القصصي، التي تتعلق ها كافة مكونات البناء القصصي، فبدوها لاتوجد قيمة للقصة؛ لأها هي من تعطي لئي

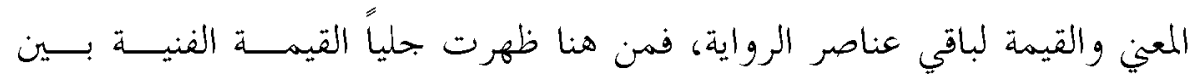
الشخصية ومكونات القصة.

لذلك " أصبحت كل عناصر السرد تعمل على إضاءة الشخصية و إعطائهـــــاك

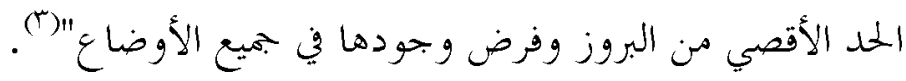




\section{口المبحث الأول: الشخصية بالشخصية}

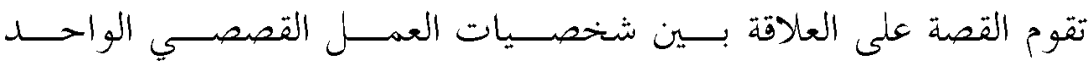

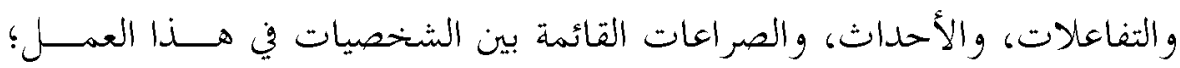
فبالنظر إلى الديوان بند أنفسنا أمام بحموعة من شبكة الشخصيات المختلفة، فمنها ما يبمع بينهم علاقات قوية ومترابطة، ومنها الشخصيات القائمــة علــى مبــــأ

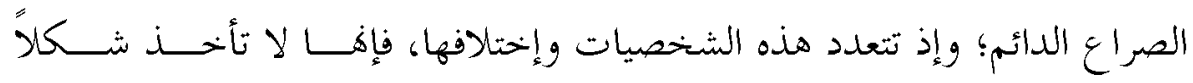

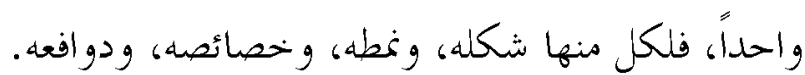

䎡

IrV

وهناك شكالان من أشكال العلاقات الإنسانية بين الشخصيات المختلفــة،

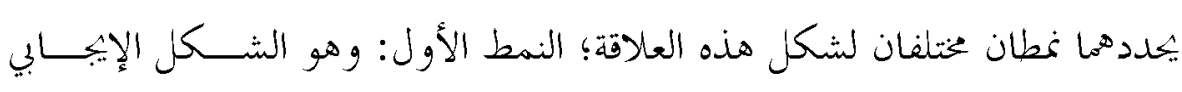
لعلاقة الشخصيات فهو دائما يقوم على قصائد الملدح والفخر؛ أما النمط الثـاني: فهو النمط السلبي الذي يقوم على قصائد الهجاء التي تحدد شكل هذه العلاقة.

ومن نماذج العلاقة الإيجابية بين الشخصيات رثاء ساعدة بن جؤية لابن أبي سفيان، وهنا أود أن أسجل ملاحظة في نظرنا غاية في الأهمية؛ فالرثاء إذ ما قار ناهُ

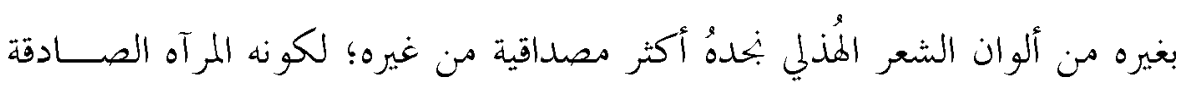

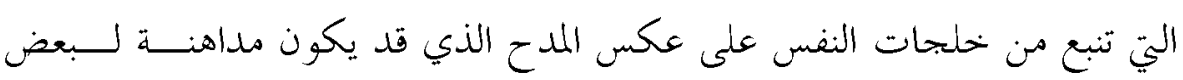
الأشخاص للظفر ببعض المقاصد، كالتقرب من شخصى، أو درءاً لسلطوية أحدهم عليه

يقول، ساعدة بن جؤية: - ماكة

في هذه الأبيات تتضح مدي عمق وأثر علاقة الشخصيتين ببعضهم البعض، فيقول ساعدة:

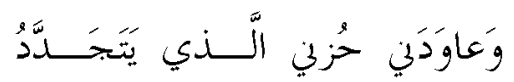

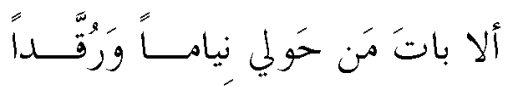


خِلالَ ضُلو عَع الصَدرِ شِرعُ مُمَدَّدُ

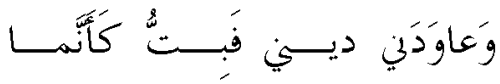

أنه عندما يهين الليل وبمسي جميع من بالحي نياماً، يتذكر خليله وصـاحبه

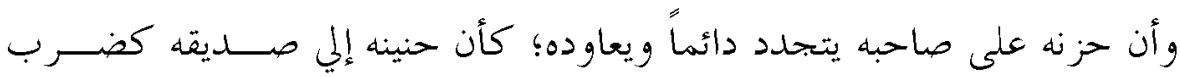
العود بين أضلاعه، ولكنه يتذكر وحشة صاحبه وأنه لو كان ابين اذ اذ أصابه ما قدر له من الموت بجانب من يوده ويكرمه لكان أهون للا بي.

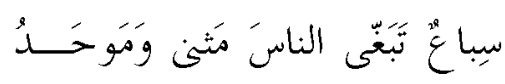

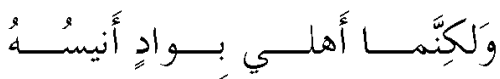
عَلى نَأيها حِملْ عَلَى الحَيّ مُقعَدُ

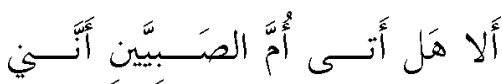

ولكنه بواد ليس له أنيس مع الذئاب والوحش، وأنه أصبح ثقيلا في وســط

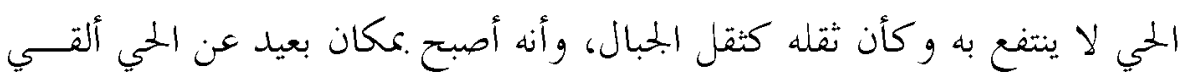
فيه وليس لديه من يقوم عليه. irs

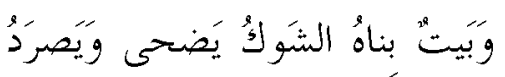

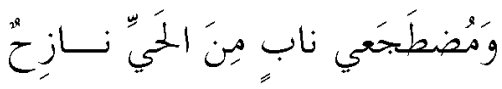

وصار بيته كشجرة الشوك كل من يمر بها تصيبه الشمس، كمــ يصــيبه البرد، فمن خحلال بيان معين الأبيات يتضح لنا حزن ساعدة بن جؤية على صاحبه،

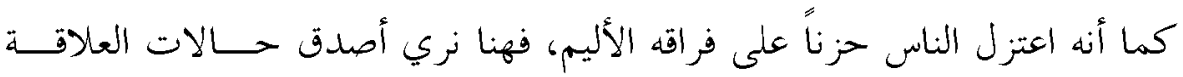

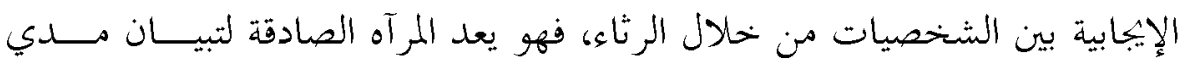
إيجابية العلاقة بين الشخصيات.

أما عن العلاقة السلبية بين الشخصيات، فالعلاقة السلبية في الشعر تتمثل من

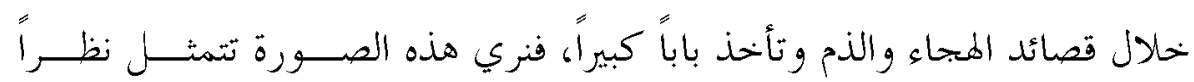


للصراعات والمشاحنات والحروب القائمة بين الأشخاص أو القبائل ؛ فمنهم مـنـ يهجو دفاعاً ومنافرة عن شخصه و ونهم من يهجو ظلماً حتي يصل لمدفه وغايته. وتتضح هذه الصورة في أبيات مالك بن الحارث يهجو فيها بين جزيمة وبين شليل:

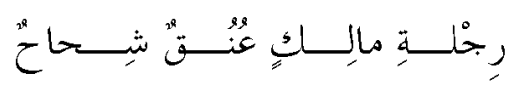

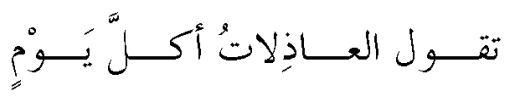

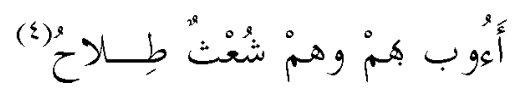
كذلك يُقِتَكـــون معـى ويونَ في هذه القصيدة لوحة تصصية تعبر عن سلبية العلاقة بين مالك بن الحارث وبني جزيمة، ونري فيها الشخصية الرئيسية وهو مالك بن الحارث كما أنه الراوي

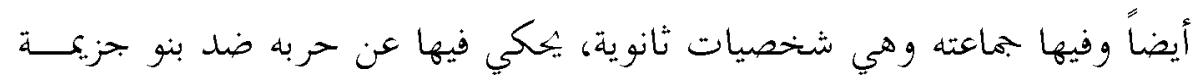

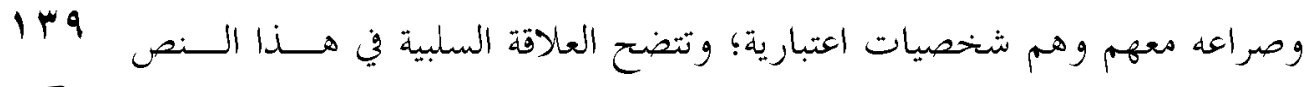

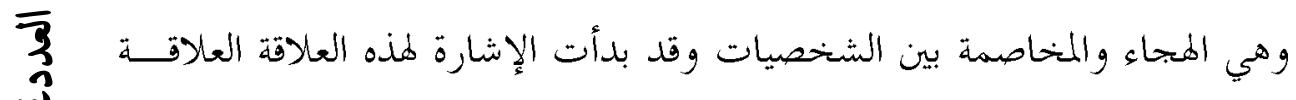
السلبية منذ البيت الأول الذي حمل من الشاعر من خلاله الإنكار لقول الحاسدين

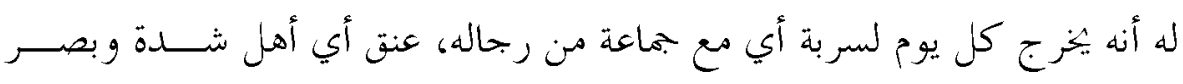

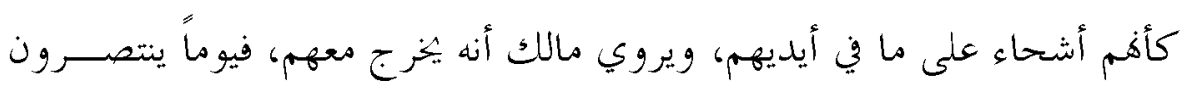

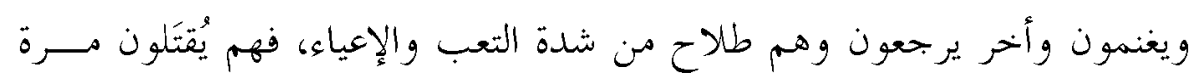

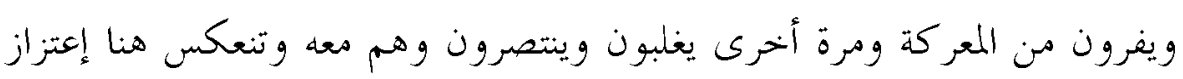
الشعر بنغسه وصورته النفسية وحالته الأيديولو جية.

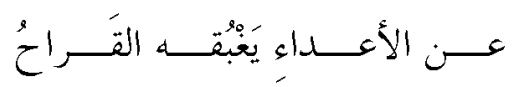

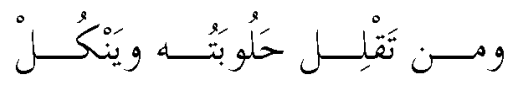

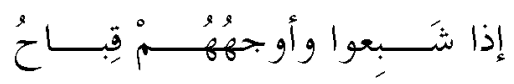

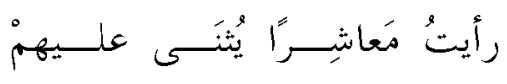




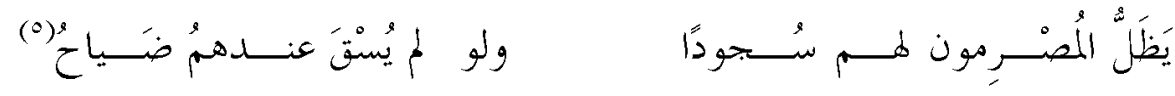

يخاطب القوم ويهزأ همم بأن من يأتيهم وقد قلت حلوبته فإن كان منهم من

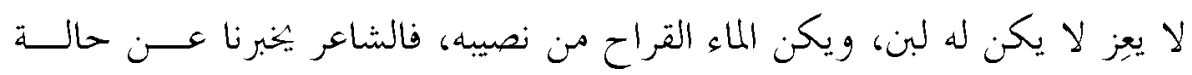

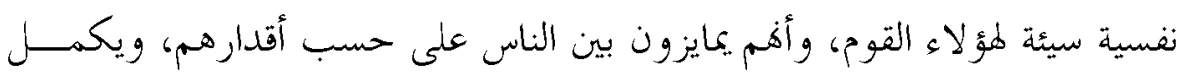
الشاعر في هجائهم بأنه رأىَّ هؤلاء القوم بني شليل يثني علىهم لأفهم ذوو مـــال

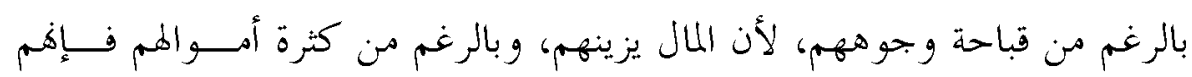
يفصحون عما بداخلهم إذا قصدهم سائل فيعطونه البن الرقيق كثير الماء. 


\section{المبحث الثاني: الشخصية بالحدث}

العلاقة بين الشخصية والحمدث علاقة طردية، حيث إن الشخصية الفاعلـــة دون حدث تكون عديمة الفائدة، فهي العلاقة الأهم داخل القصــيدة القصصــية،

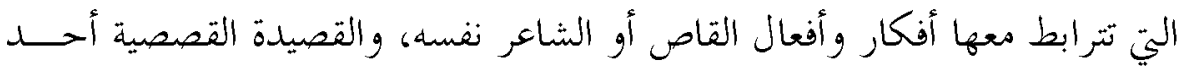
مكوناةا الرئيسة الأحداث المباشرة وغير مباشرة داخل سياق القصيدة " ويخلــص

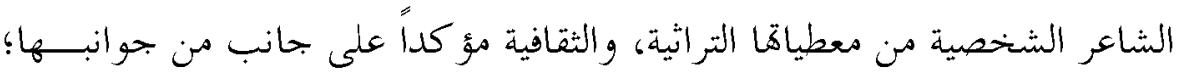

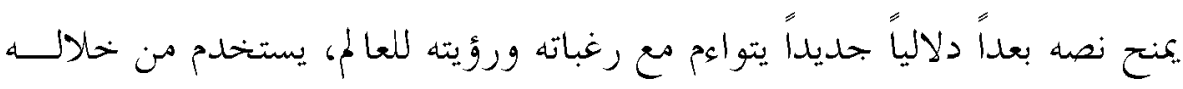
منظور التقابل مع كينونته، من حلال الأصوات السردية المتنوعة، فلا يوجد حدث رداث دون شخصية وليست هناك شخصية سكونية دون حر كة أو فعل" (1).

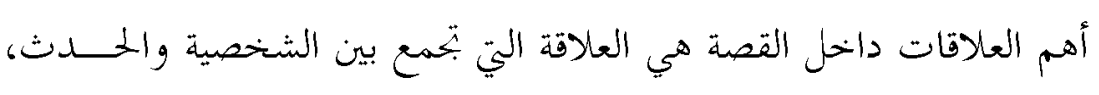

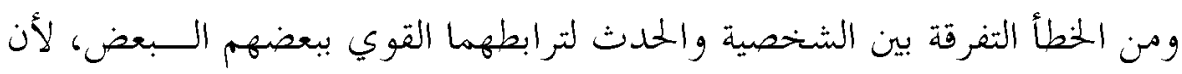

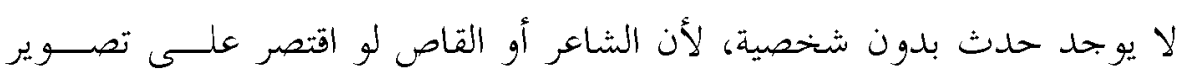
الحددث دون الإخبار بمن قام هذا المحدث لأصبحت حكايته بحرد إخبار عن شئ. ومن تُمّ فالر ابط بينهما أقوي من أن يستغني أحدهما عن الأخر، نظراً للتــأثير وطردية العلاقة بينهما، " فالقاص يعرض علينا الشخصيات متفاعلة مع أحســـــــاثها، فالقصص تعرض صورة صادقة من الحياة، بالرغم من أذا بشعة وقاسية في عرضها، لكنها تتصف بالصدق والأمانة في عرضها وتتميز بدقتها في التصوير دون تملق من الكاتب لذوق القارئ، فالموضو ع ليس كل شئ في القصة بل ترابط الشخصــيات مع أحداثها" (v)

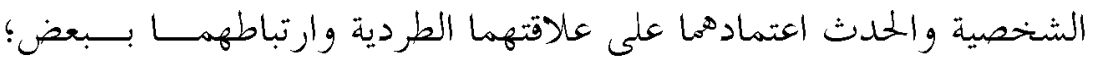
يولد لنا علاقة ديناميكية بين كلا الطرفين، فالحدث يقوم بدور أساسي يعتمد على

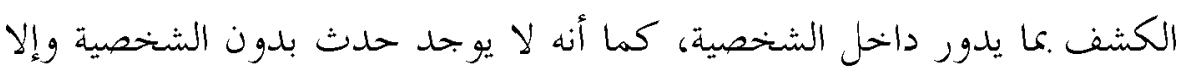


تكون سكو نية، فتفقد وظيفتها الرئيسية، فالشخصية هي من تقوم بدفع الأحداث إلي الأمام أو ثباتها أو اسراعها وابطائها على حسب حركة كرة الشخصـيات داخهل النص القصصي والشعري، أو كما يوجهوا الراوي؛ لكنه يجب عليــهـ أن يســيّر كالهما في إبتاه واحد حتي لايفقد أي منهما قيمته داخل حركة النص. لنص.

1- أثثير الثخصية في الحدث:

طبيعة العلاقة التي تربط بين كل من الشخصية والحمدث، تتصف بــالتحور

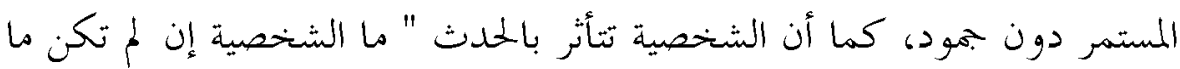
تقرره الحادثة؟ وما الحادثة إن لم تكن توضيحاً للشخصية؟ فعلى الرغم من كوهنا

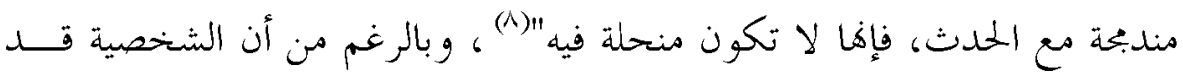

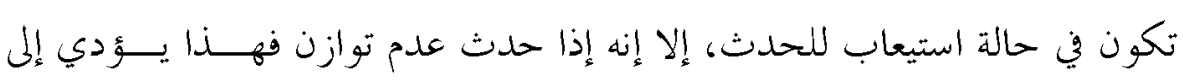
عدم التطور في البناء السردي للقصة.

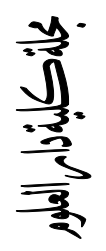

وفي بعض القصص تشغل الشخصية حيزًا كبيراً في بنية الســرد، وتكـــون

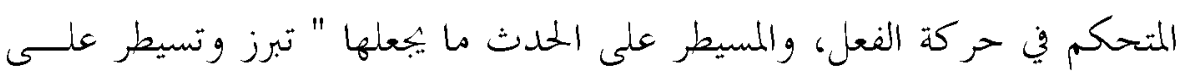

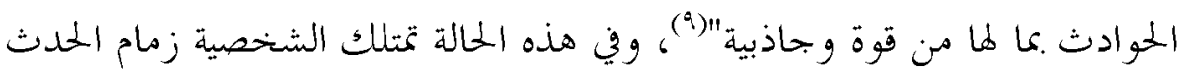
$\overline{3}$
क
0

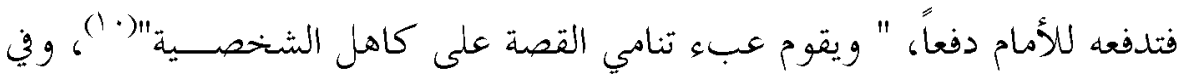
هذه الحالة تصبح الشخصية مسيطرة " على الحوادث فنحر كها تبعاً لرغباها ووفتاً

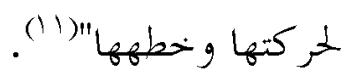
ومن شواهد الحدث الذي يصدر عن الشخصية، يقول أبو خراش:

أنْ البُكير اللذى أَسعَوْا به هَمَــلُ

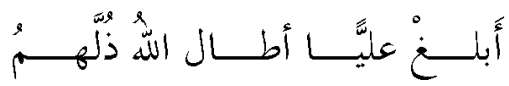

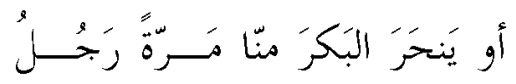

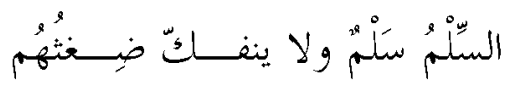




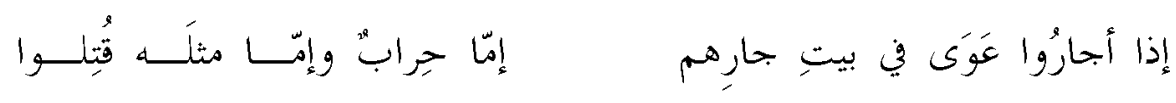

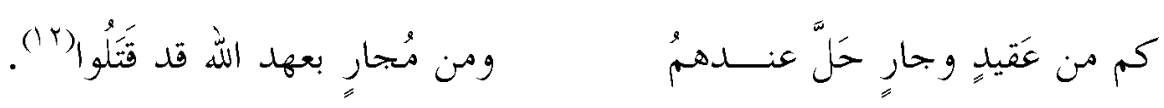

هذا النص وجه الشاعر أبو خراث مجموعة من الأفعال والأحداث التي تصدر

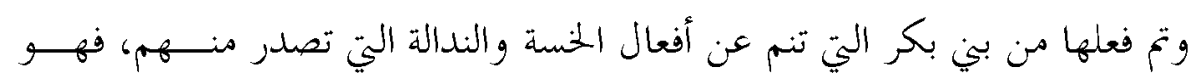

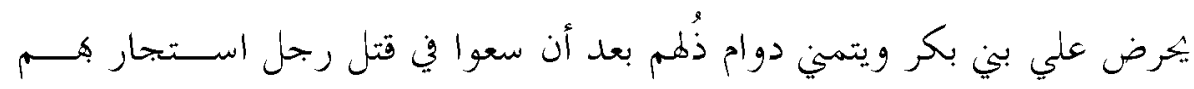

$$
\text { وجاورهم، فلم يمفظوه أو يدافعوا عنه وحاربوه . }
$$

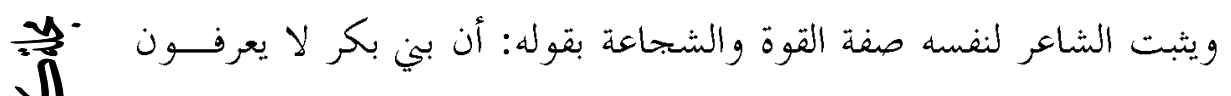

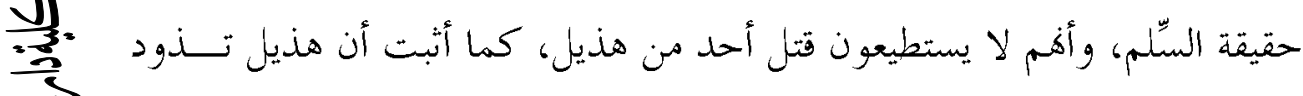

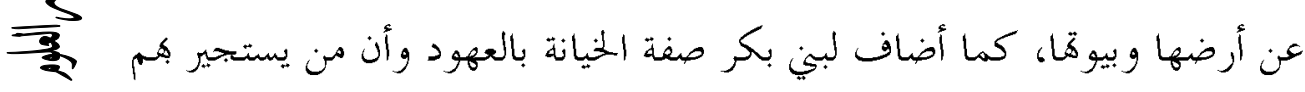
سواء كان عدوًا أو حليفاً، فإهم يسعَون في قتله.

$\overline{3}$

\section{ب- تأثير الحدث في الثخصية:}

الشخصية أحياناً تكون متسيدة الحدث، فكما أن الحدث يتأثر بالشخصــية

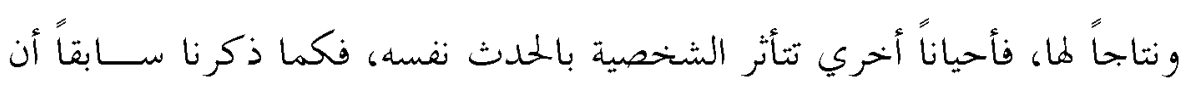

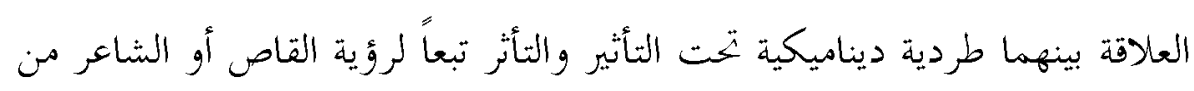
خلال البنية الروائية للقصيدة ومدي قدرته علي توظيف الأشخاص والأحســــاث المترابطة بينهم داخل النص.

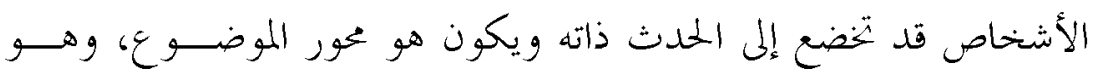

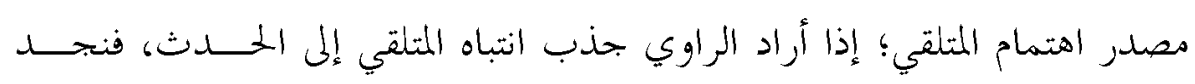

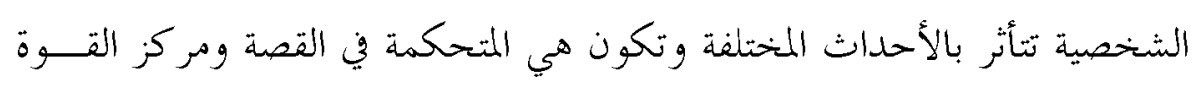


والسيادة، " تكون طبيعة الأحداث هي المتحكم في رسم الشخصيات، وإعطائهــــا

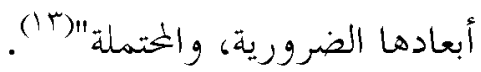

" كل ما يحدث من أحداث في القصة لابد أن يمســـها الحـــــث أو الفعـل

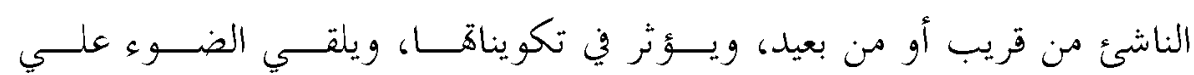

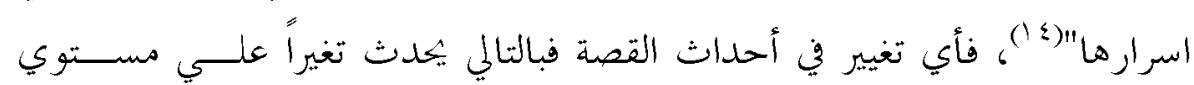

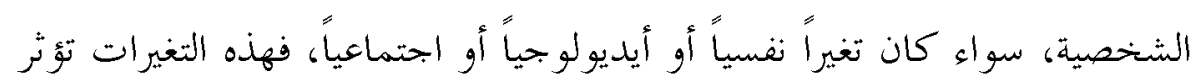
على إدراك الشخصيات للحدث في حد ذاته أو للعالم المخيط به. تأثير الحلدث علي الشخصية إما أن يكون إيبابياً أو سلبياً، ويشــمل هــــا

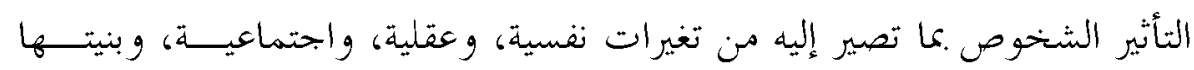

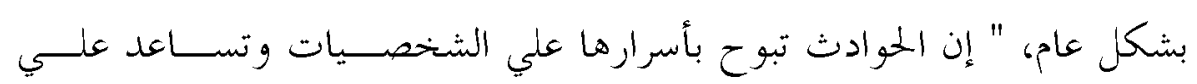
تطويرها ونموها، وترك الأثر فيها"(10).

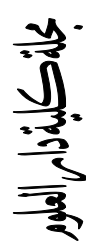

ومن شواهد تأثر الشخصية بالحدث، قول ابو خراش في هجرة ابنــهـ أثنــاء

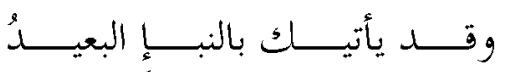
خحافة عمر:

تجمِِّ وقد يأتيـــكَ بالأخبــارِ مــنـ لا

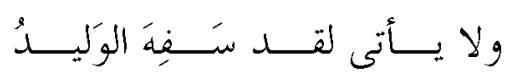

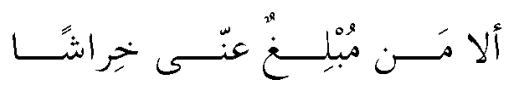
33 ابته الشاعر إلي توظيف شخصيته من خحالال تأثرها ببعض الأحداث، وهــي هجرة ابنه خراش في عهد سيدنا عمر بن الخطاب، وخروجه للغزو في بلاد الشام؛

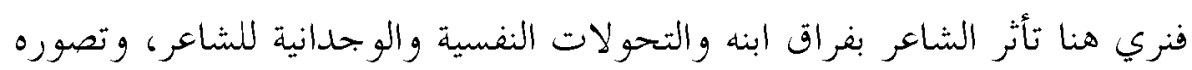
بأنه أصبح دون ناصر أو معين، بعد أن هلك أهله، وقتل إخوته. 


\section{بنية الشخصية في القصيدة الشعرية عند الهذليين}

فبعد أن بيَّن الشاعر حالته وتأثزه بفراق ابنه، وأنه يريد من يخبره عن أحواله

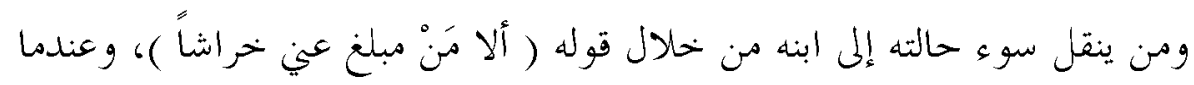

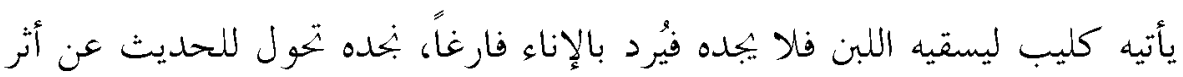
الحدث والفراق ووقعه علي نفسه، بأنه بعد هجرة ولده أصبح الخير الذي يصــيبه

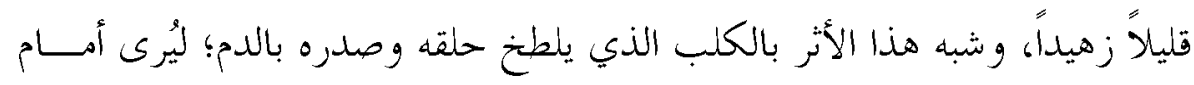
الناس أنه صاد ولكنه لم يصد شئ. وتهن.



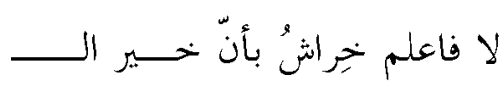

كمخصنوب اللّبان ولا يصيدُ(1).

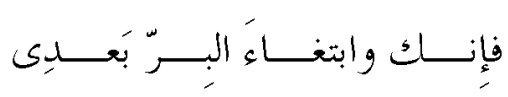

أبرز الشاعر من خلال هذه التجربة أثر الهجر والفراق علي نفسه، مما حاذاه

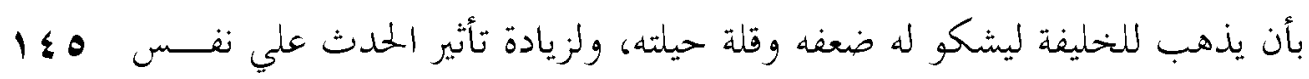

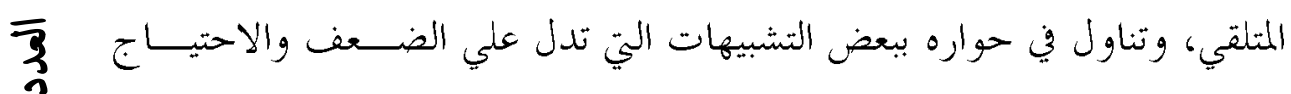

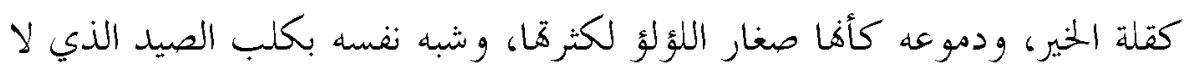

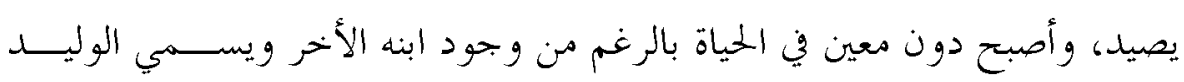
وعبدهُ كُليب. 


\section{المبحث الثالث: الشخصية بالزمان}

أهمية الزمان تبرز من خحلال علاقته بالشخصــية- بجانــبـ المككـان- لأن

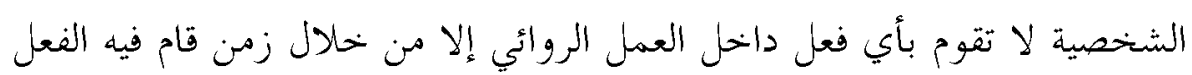

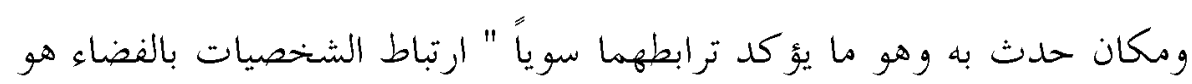

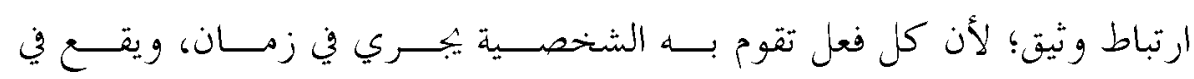
مكان" (19) (")

ارتباط الشخصية بالزمن من أهم مظاهره: بتجسيد العمر الــزمين، ومــــي

التطور الفكري والاجتماعي؛ فهو يصاحب الشخصية علي طول سير الرواية، ولا

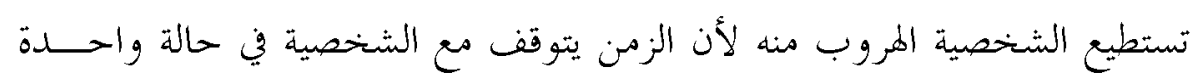

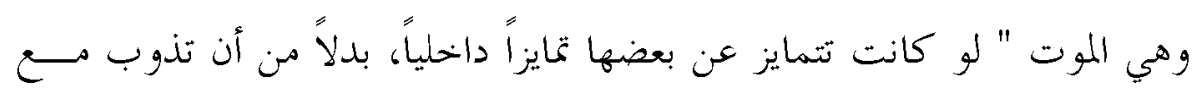

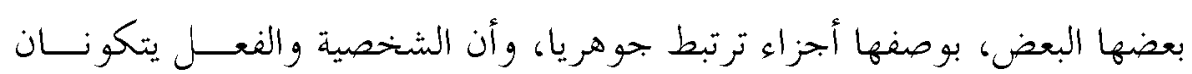

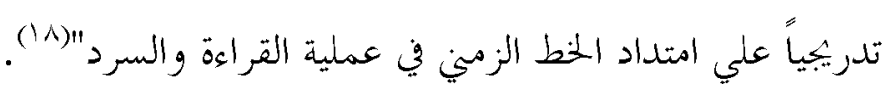

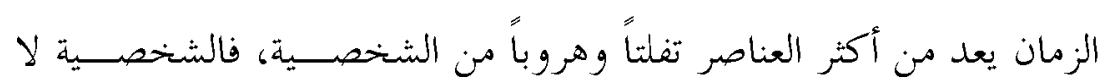

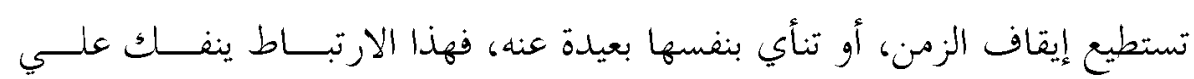
势 حسب سير العمل أو رغبة المؤلف.

الزمان وعلاقته بالشخصية يولد لنا أبعاداً جديدة، ودلالات أكثر من خلال

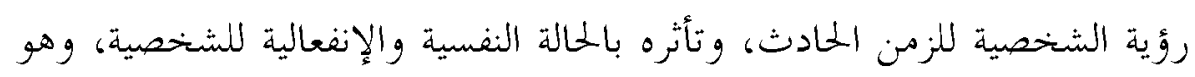

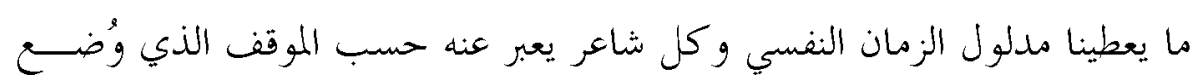
فيه. وفي تلك العلاقة تتجلى الشخصية والزمن قول: أمية بن أبي عائد:
مــن النائبــاتِ بعـافٍ وعـــال

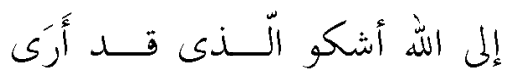




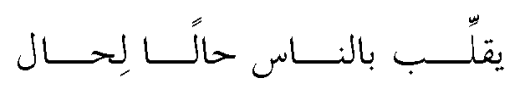

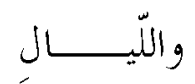

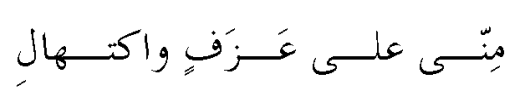

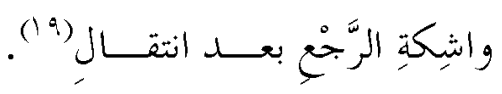

وإظلالَ هـــا الزمــانِ الــنَى

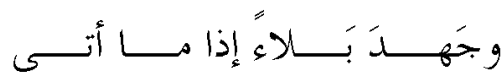

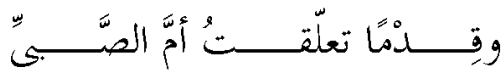

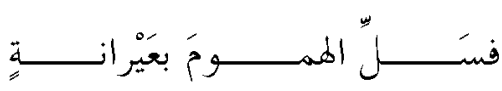

اعتمد الشاعر علي توظيف الزمان ( النائبات- الأيام- الليالي) .مســلولولات

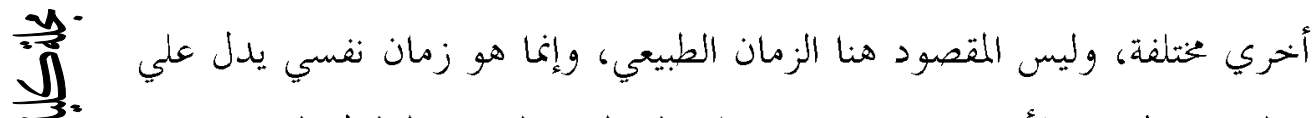
حالة من الحزن والأسى، حيث اعتمد علي التوظيف النفسي لمدلول الزمن بنوائبه

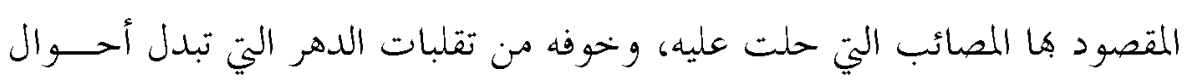
الناس ويقصد هنا تبدل حاله إلى الأسوأ، وما تحمله من جهد والبلاء عليه.

$\overline{3}$
3
0

وابتحه الشاعر إلى توظيف دلالة ورمزية الليل الذي أدرك من خلالهــهـ أن لا

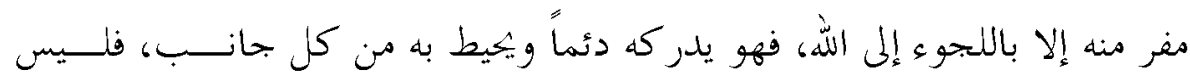

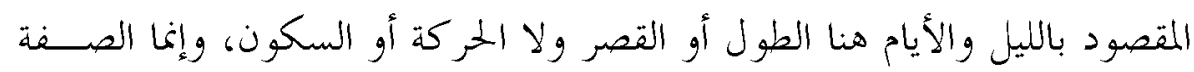
والدلالة الواقعة علي الحالة النفسية للشاعر، بل صفة الإدراك وسيطرة الهم والبلاء

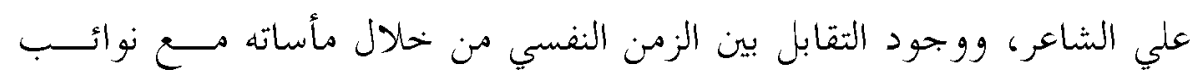
الدهر، والزمن الطبيعي وهو عزوفه عن النساء و كهولته.

وظلَّف الشاعر الزمن من خلال تصوير همومه بالعير التي تسير بين الأحجــــر

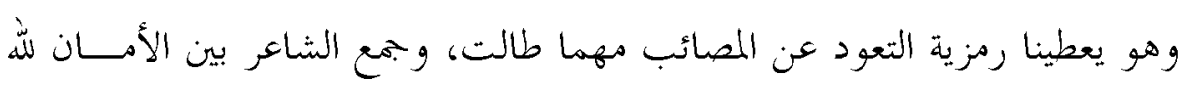
والخوف 


\section{口الابعث الرابع: الشخصية باليكان}

طبيعة العلاقة بين الشخصية والمكان تنبع من كوفما مترابطين ومتعــددي

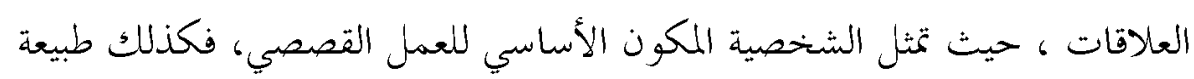

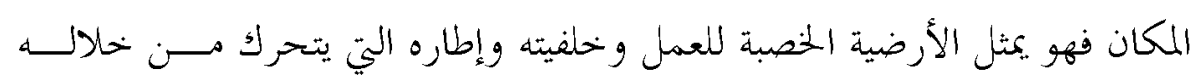

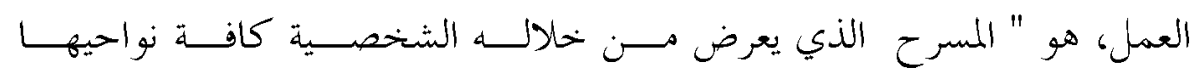

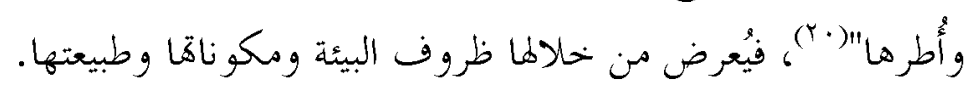
تأخد العلاقة بين الإنسان والمكان صوراً وأشكالاً متعددة: أن يأني المكـــان

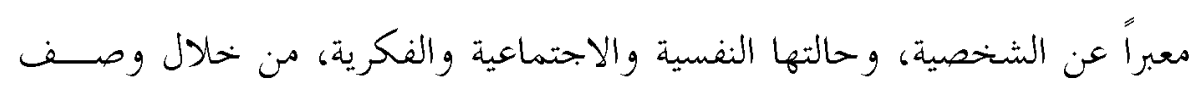

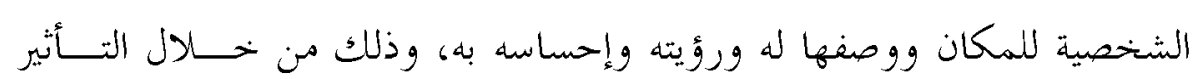

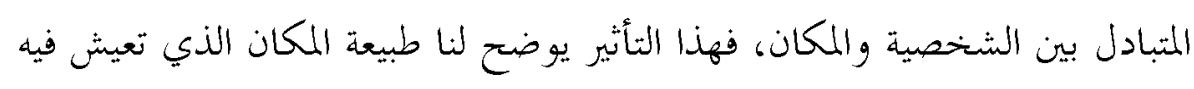

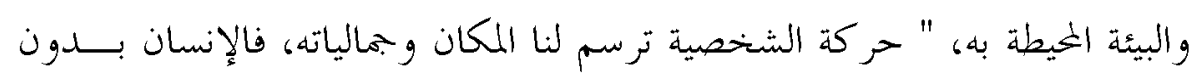
مكان لا حياة فيه" (1).

فالشخصية تتأثر بالمكان لأكا تعيش فيه وتتعايش معه، وتتطبع بما فيه مــن

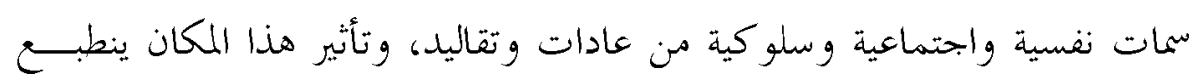

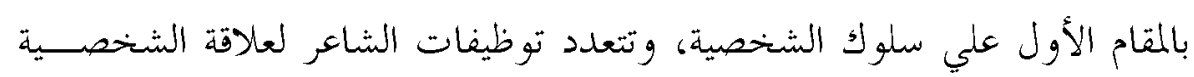

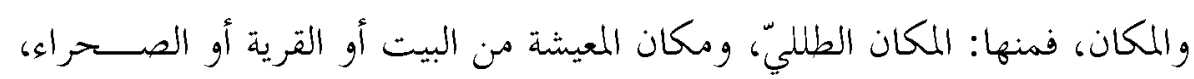

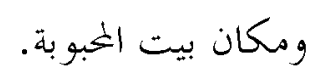

$$
\text { ومن شواهد علاقة الشخصية بالمكان، قول (أبو ذؤيب): }
$$

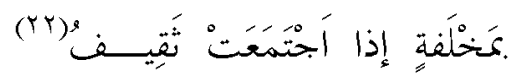

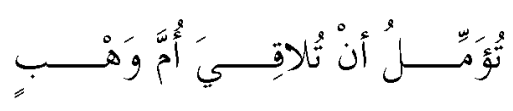

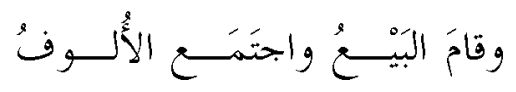

إذا بُنِيَ القِبــابُ علــى عُكـــاظٍ 


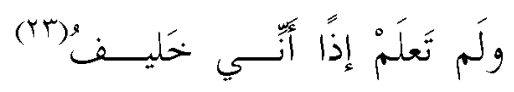

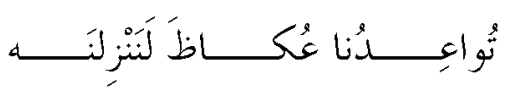

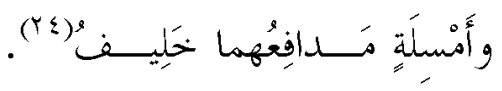

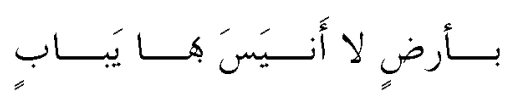

تتشكل صورة العلاقة بين الشخصية والمكان من خلال شخصــيات أبــو

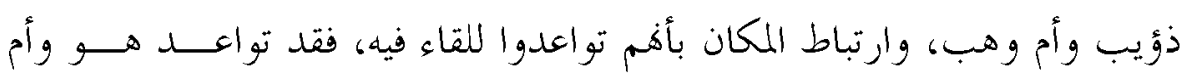

وهب أن يتلاقوا في طريق أو جبل عندما يقام سوق عكاظ في موعده، وإختــار أرض يباب في سهل بين جبلين لا يوجد بها أحد، فتشكلت صورة المكان ووصفه

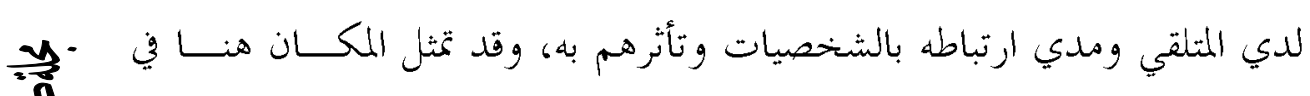

$\frac{1}{5}$

$1 \leq 9$ عكاظ، وهو مكان و اقعي له صلة بإحساس الشاعر ومرتبط به، و حددت صفاته.

$\overline{3}$
3
0 


\section{خاثمة:}

الحمد للّ رب العالمين في الأوليين والأخرين، والصلاة والسلام علي أشرف

خير خلق الله؛ وبعد

لقد حاولت في هذه الورقة البحثية التجول داخل بينة الشخصـية في شـعر

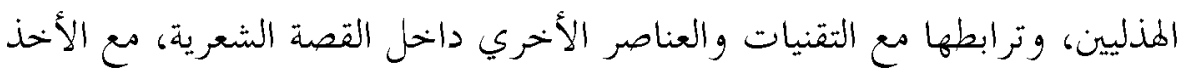

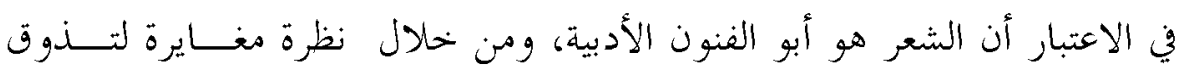
وتحليل الشتر.

بند أن الشعر، هذا الإرث العظيم فيه ما يمتوي على كثير من ملامح القصة

وبدايات نشأها، ويتضمنها الشعر، وإن كانت القصة ليست مخور القصيدة، وإنما

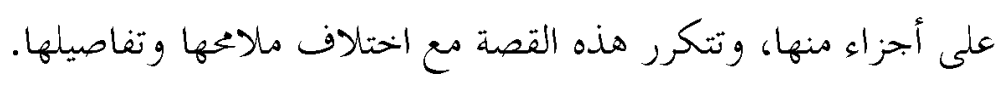
ويمكن استخلاص بعضاً من نتائج هذه الورقة البحثية، فيما يلي:

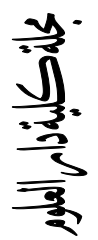

1- الشخصية هي محور العمل القصصي والبناء، فبناء الشخصية هو من يــــدد اللغة المستخدمة في الخطاب، في العمل القصصي. Y-تقوم القصة داخل الشعر على العلاقة بين شخصيات العمل القصصي الواحد والتفاعلات، والأحداث، والصراعات القائمة بين الشخصيات في هذا العمل. r- أن القصص مستمدة من الواقع الحياتي للشعراء الهذليين. ع-توظيف الشعراء لمحموعة من التقنيات والعناصر الروائية، والتـــــابط بينـــها؛ كالشخصية والزمان والمكان. 


\section{口 قائمة بأهم المصادروالمراجع}

\section{أولاً: المصادر:}

1- الشنقيطي: ديوان الهذلين، تحقيق أحمد الزين، دار الكتب المصرية،

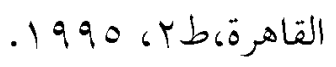

Y-السكري:شرح أشعار الهذليين، تحقيق عبدالستار فراج، دار العروبة، القاهرة،

$$
.1970
$$

$$
\begin{aligned}
& \text { r-الأصفهاني، أبي الفرج: الأغانيكج الr. } \\
& \text { ع-الزبيدي،: تاج العروس، جب إن }
\end{aligned}
$$

ه-الأصمعي: الأصمعيات، تح عبد السلام هارون، دار المعارف، القاهرة، طب،

$$
. r \cdot 11
$$

101

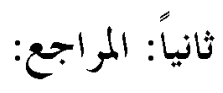

$\overline{3}$
3
0

1-حسن بحراوي: بنية الشكل الروائي، المركز الثقافي العربي، المغرب، طله

$$
.81999
$$

ץ-عبد الملك مرتاض: في نظرية الرواية بحث في تقنيات السرد،الخلس الوطين

$$
\text { للثقافة والفنون والأداب، الكويت، } 919 \text { أم. }
$$

r-عبدالناصر هلال: آليات السرد في الشعر العربي المعاصر، مركز الحضلارة،

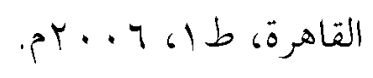

ع-محمـــد زيدان: البنية السردية في النص الشعري، الميئة العامة لقصور الثقافة،

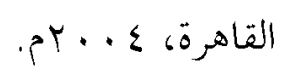

ه-معــــ يوسف بنمم: فن القصة، دار بيروت للطباعة والنشر، بيروت، ط اه

$$
.81907
$$


7-موفق مقدادي، البين الحكائية في أدب الأطفال، عالم المعرفة، الكويت، عدد

$$
.5 r \cdot 1 t, 17964 t
$$

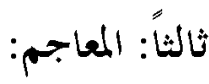

1-ابن منظور: لسان العرب، دار المعارف، القاهرة، 11 بـ.

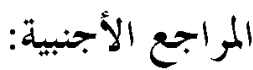

ا-ووالاس مارتن: نظريات السرد الحلديثة، ترحياة جاسم، البحلس الأعلى

اللثقافة، القاهرة، 1991 19.

\section{الهوامش والإحالات :}

(1) انظر، عبد الملك مرتاض: في نظرية الرواية بحث في تقنيات السرد، المخلس الوطني للثقافة

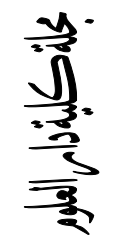

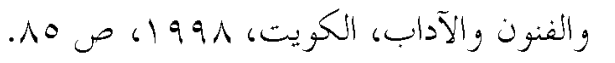

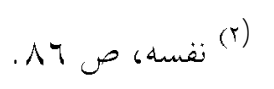

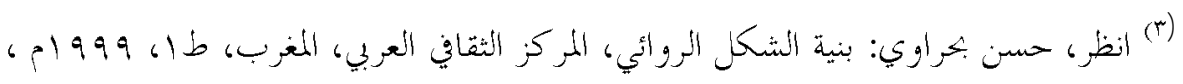

$$
\text { .Y. }
$$

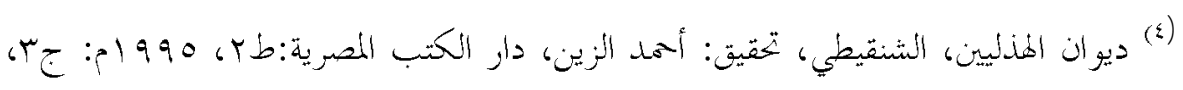

ص:1

$$
\text { (0) }
$$

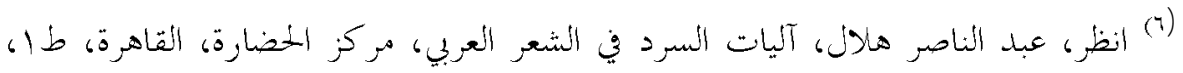

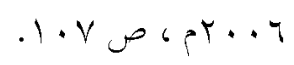

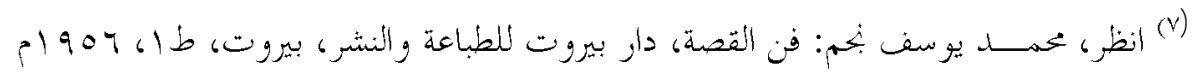

$$
\text { or: : : م : }
$$

() انظر، والاس مارتن، نظريات السرح المحديثة، ص00 100، . 17 1. 


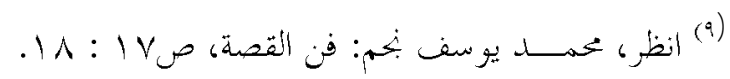

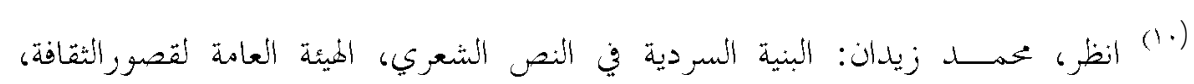

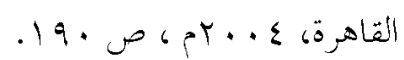

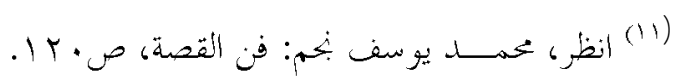
(r)

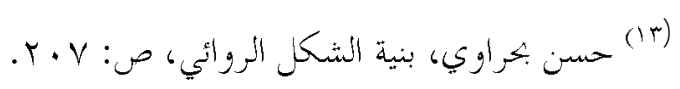

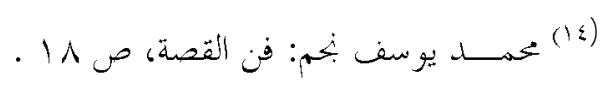

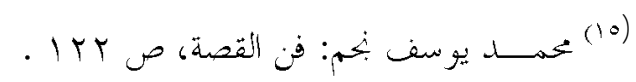

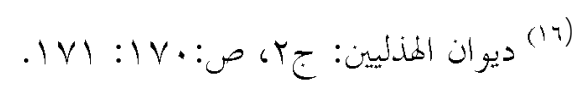
10 (V) انظر، موفق مفدادي، البين الحكائية في أدب الأطفال، عالم المعرفة، الكويت، عدد بوجب، .1 T

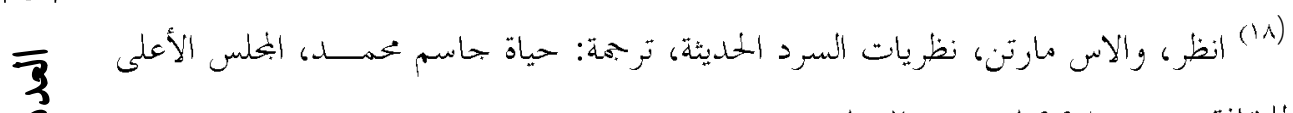

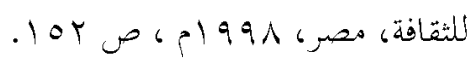
IVE:IVT: (19)

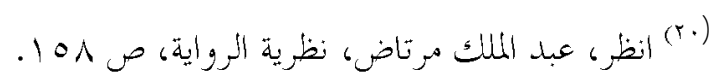

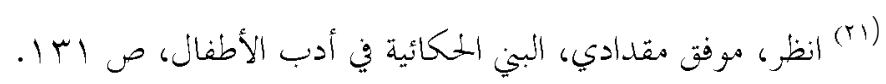
(Tr) في رواية: "أم عمرو" هكان قوله: " أم وهب"، ورواية أم عمرو عن أبي بكر الحلوانيّ gad. وفي تاج العروس للزبيدي، جبا، صول ا، المنلفة، كمرحلة: الطريق، في سهل كان أو جبل، ومخلفة متى: حيث ينزل الناس. (rT) عكاظ: رواية الأصمعي، وفي رواية السكري: " تواعدنا الربيق" والربيق: واد بالخجاز.

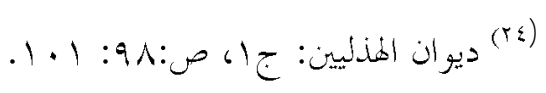

